\title{
Association between Helicobacter Pylori Infection and Alopecia Areata: A Study in Iranian Population
}

\author{
Elham Behrangi ${ }^{1}$, Parvin Mansouri ${ }^{2}$, Shahram Agah ${ }^{3}$, Nasser Ebrahimi Daryani ${ }^{4}$, Marjan Mokhtare ${ }^{5}$ \\ Zahra Azizi ${ }^{6}$,Mona Ramezani Ghamsari ${ }^{7}$, Masoumeh Rohani Nasab ${ }^{8}$, Zahra Azizian, ${ }^{9}{ }^{*}$
}

1. Associate Professor, Department of Dermatology and Laser Surgery, Clinical Research Center, Rasoul-e-Akram Hospital, Iran University of Medical Sciences, Tehran, Iran

2. Department of Dermatology and Laser Surgery, Skin and Stem Cell Research Center, Tehran University of Medical Sciences, Tehran, Iran

3. Professor, Department of Gastroenterology and Hepatology, Colorectal Research Center, Iran University of Medical Sciences, Tehran, Iran

4. Professor, Department of Gastroenterology and Hepatology, Tehran University of Medical Sciences, Theran, Iran

5. Assistant Professor, Department of Gastroenterology and Hepatology, Colorectal Research Center, Iran University of Medical Sciences, Tehran, Iran

6. Researcher, Iran University of Medical Sciences, Tehran, Iran

7. Neurology Resident, Iran University of Medical Sciences, Tehran, Iran

8. Assistant Professor, Department of dermatology, Iran University of Medical Sciences, Tehran, Iran

9. Dermatology Resident, Skin and Stem Cell Research Center, Tehran University of Medical Sciences, Tehran, Iran

\section{* Corresponding Author:}

Zahra Azizian, MD

Skin and Stem Cell Research Center, Tehran University of Medical Sciences, Tehran, Iran Telefax: + 982166560333

Email: Azizian_Z@yahoo.com

Received: 29 Nov. 2016

Accepted: 28 Feb. 2017

\section{ABSTRACT}

\section{BACKGROUND}

Alopecia areata is an immune mediated inflammatory hair loss, which occurs in all ethnic and age groups, and both sexes. However no significant etiology has been known for this disease. Helicobacter pylori (H. pylori), is an organism colonized in gastric mucosa. This bacterium has been associated with certain extra-digestive dermatological conditions. The causal relationship between alopecia areata and $H$. pylori infection has been discussed in literature. Therefore, we conducted this study to evaluate the prevalence of $H$. pylori infection in patients with alopecia areata and assess the risk of this infection in patients with this disease in order to determine its potential roles in the physiopathology of this disease.

\section{METHODS}

Between 2014 and 2015, we prospectively studied 81 patients with alopecia areata and 81 healthy volunteers with similar age and sex. Patients without any history of $H$. pylori infection were included in the study and underwent urease breath test. All results were analyzed using SPSS software (version 21.0) and $p$ value $<0.05$ was considered as statistically significant.

\section{RESULTS}

81 patients and 81 controls with the mean age of $34.9 \pm 11.6$ and $38.2 \pm 13.4$ years were studied $(\mathrm{p}=0.097) .48(59.3 \%)$ and $45(55.6 \%)$ individuals were male, in cases and control groups respectively $(\mathrm{p}=0.634)$. The result of urea breath test (UBT) was positive in $43(53.1 \%)$ patients in cases and $27(33.3 \%)$ individuals in control group, which was significantly different $(\mathrm{p}=0.011)$. The risk of H. pylori infection in alopecia areata was 2.263 (95\% CI: 1.199-4.273).

\section{CONCLUSION}

The results of our study showed significant difference between $H$. pylori infection in individuals with and without alopecia areata, which shows that $H$. pylori contamination may be effective in physiopathology of alopecia areata. Therefore these results should be tested in large multivariable cohorts and controlled trials to reach more accurate evidence in the future and to generalize this idea to larger population.

\section{KEYWORDS:}

Helicobacter pylori; Alopecia areata; Urease breath test

Please cite this paper as:

Behrangi E, Mansouri P, Agah S, Ebrahimi Daryani N, Mokhtare M,Azizi Z,Ramezani GhamsariM, Rohani Nasab M, Azizian Z. Association between Helicobacter Pylori Infection and Alopecia Areata: A Study in Iranian Population. Middle East J Dig Dis 2017:9:107-110. DOI: 10.15171/mejdd.2017.59.

\section{INTRODUCTION}

Alopecia areata is a chronic inflammatory disease leading to non-scar forming hair shedding. Except the head, as the most common site of involvement, other hairy locations may be affected and in severe cases all parts of the body would develop alopecia. ${ }^{1}$ Alopecia areata has a prevalence rate of 1 per 100,000 
subjects and a risk coefficient of $2 \% .{ }^{1}$ Until now definite etiology is not known but some evidence have shown autoimmune underlying mechanisms of this disease. ${ }^{2}$ Histological findings are the most important documents that show the presence of T-lymphocyte infiltration around the terminal hair follicles. ${ }^{1}$ T-cell mediated perifolliculitis leading to normal cell cycle disruption is one of the proposed etiologies. ${ }^{1}$ Helicobacter pylori (H. pylori) is a microaerophilic gram negative bacteria colonized in the stomach ${ }^{3}$ leading to contamination of $50 \%$ of worldwide population. ${ }^{4}$ Currently it has been shown that $H$. pylori may be related to various non-gastrointestinal disorders including chronic urticaria ${ }^{5-7}$, roseace ${ }^{5-8}$, psoriasis ${ }^{8,9}$, Schönlein-Henoch purpura ${ }^{10}$, Behçet disease ${ }^{11,12}$, chronic itching ${ }^{13}$, progressive systemic sclerosis ${ }^{14,15}$, Sjögren syndrome ${ }^{16,17}$, and sweet syndrome $\cdot{ }^{18}$ Most of these diseases have shown partial or complete improvement after H. pylori eradication. ${ }^{7,9,19-21}$ Different mechanisms have been proposed including; formation of antigen-antibody complexes and cross-reactive antibodies with molecular behavior pattern. ${ }^{21-23} \mathrm{H}$. pylori would promote local inflammatory and chronic immune responses ${ }^{24-26}$ leading to release of inflammatory mediators including interleukin-1, tumor necrosis factor alpha (TNF- $\alpha$ ), interferon (INF) gamma, leukotriene (LT) $\mathrm{C} 4$, and platelet-activating factors (PAF). These mediators may be involved in the pathogenesis of skin diseases.$^{27,28}$ Since there are few studies ${ }^{29-31}$ on the correlation between H. pylori and alopecia areata and considering the importance of this issue and undetermined role of $H$. pylori in alopecia areata, this study was performed to determine the possible association between $H$. pylori infection and alopecia areata in Iranian population.

\section{MATERIALS AND METHODS}

In this case-control study, of the subjects attending to dermatology clinic of Rasool-Akram Hospital, Tehran, Iran between 2014 and 2015, 81 patients with alopecia areata and 81 patients without alopecia areata were enrolled as case and control groups, respectively. The subjects who had positive history of treatment for $H$. pylori were excluded. The status for $H$. pylori was checked by urea breath test (UBT) in Sara Nuclear Medicine Center. The subjects with positive UBT test were treated in Gastroenterology Clinic by standard regimen for eradica- tion of $\mathrm{H}$. pylori including amoxicillin $(500 \mathrm{mg}, 2$ per 12 hours), clarithromycin (500mg, 1 per 12 hours) and pantoprazole ( 1 per 12 hours) for a two-week period. The results were presented as mean \pm standard deviation for continuous variables and as percent for categorical variables. The statistical analysis was performed by SPSS software (version 21.0) utilizing independent sample t, Chi-Square, and logistic regression tests. The significance level was considered as 0.05 .

This study was approved by Ethics Committee of Iran University of Medical Sciences. The Helsinki Declaration was respected during the study.

\section{RESULTS}

\section{Patients' characteristics:}

Total of 81 cases and 81 controls with mean age of $34.9 \pm 11.6$ and $38.2 \pm 13.4$ years were studied $(p=0.097)$. Amongst all, 48 (59.3\%) and $45(55.6 \%)$ patients were male, in cases and control groups, respectively ( $p=0.634$ ).

\section{UBT results:}

The result of UBT was positive in 43 (53.1\%) patients in the cases and 27 (33.3\%) subjects in the control groups, respectively which was significantly different $(p=0.011)$.

Risk of $H$. pylori infection in alopecia areata:

By risk analysis, the risk of $H$. pylori infection in alopecia areata was 2.263 (95\% CI: 1.199-4.273). Multivariate logistic regression analysis of two treatment groups with adjusting the effect of sex and age as confounding variables also showed significant risk of $H$. pylori infection in alopecia areata with odds ratio of 2.090 $\pm(1.090-4.009)$.

However, sex had no significant relationship with the results ( $p=0.794)$. Among 93 men, $41(44.1 \%$ ) had positive UBT results. This is while among 69 women, 29 (42\%) had positive H. pylori test $(p=0.79)$. This result showed that sex had no significant effect on the risk of $H$. pylori infection in alopecia areata. Moreover age of the patients had significant effect on the risk of H. pylori infection in alopecia areata. However the results showed the lower age (33.2 vs 39.1 years) was significantly related to positive response $(p=0.003)$.

\section{DISCUSSION}

Alopecia areata is a chronic inflammatory disease seen in both sexes and all ages. In severe cases all parts of the 
body would develop alopecia. ${ }^{1}$ Despite importance of this disease, definite etiology is not yet illuminated. H. pylori has been shown to have an association with skin diseases as a super-antigen .5,6,9,11,12,15,32-34 However, this study was performed to demonstrate the association between alopecia areata and $H$. pylori infection as a possible etiology of alopecia areata. In this case-control study, 81 patients with alopecia areata and 81 subjects without the disease were enrolled as case and control groups, respectively. Mean age was 34.9 years in the cases and 38.1 years in the control group, respectively. 48 (59.3\%) and 45 (55.6\%) patients were men, in the cases and the control groups, respectively. Both age and sex were matched in the two groups. UBT showed positive result in 53.1\% (43) patients in the cases and $33.3 \%$ (27) in the controls, which was significantly different ( $p=0.011$ ), showing two fold higher risk of alopecia areata in subjects with $H$. pylori contamination. Among 93 male subjects, 41 patients (44.1\%) had positive test result for $H$. pylori while 29 women (42\%) had positive results showing no statistically significant difference. The mean age was 33.2 years in those with positive results and 39 years in those with negative results showing higher $H$. pylori infection rate in younger subjects. A case report by Campuzano-Mayag 30 described a 43-year-old man who had history of alopecia areata for 8 months and had no improvement during treatment. His disease remitted after $H$. pylori eradication. This is while in a study by HZ Abdel-Hafez and colleagues, on 31 patients with alopecia areata and 24 healthy volunteers for the presence of $H$. pylori surface antigen (HPS Ag), despite higher HPS Ag in patients with alopecia areata, it was not statistically significant.29 Moreover, in a study by Rigopoulos and co-workers 31 on 30 patients with alopecia areata and 30 healthy controls who were matched by age and sex, IgG antibodies of $H$. pylori were tested. However, the results showed no statistical difference in seropositivity of the two groups ( $p=0.3$ ). But in our study there was significant difference between $H$. pylori infection in patients with and without alopecia areata and it was found that $H$. pylori infection would increase the chance of alopecia areata more than two times. In our study, it seems that $H$. pylori contamination may be effective in the physiopathology of alopecia areata. Hence these results can propose a hypothesis of probable correlation between these two diseases and the possible need for including this test for the assessment of this bacterium in the list of diagnostic approaches for patients with alopecia areata. However due to the limitation of our study including the type of our study (since a case control study is a preliminary study with lower costs to find out a correlation among possible factors and diseases) and its weakness in controlling confounding variables and other possible factors that may be responsible for positive results, other studies with high rank of evidence should be performed to express more certain results. Another limitation of our study was the lack of multiple laboratory tests for better identifying H. pylori infection. Therefore, our positive results should be tested in larger multivariable cohorts and controlled trials to reach more accurate evidence in the future and to generalize this idea to larger population.

\section{ACKNOWLEDGEMENTS}

This study was supported by a grant from Iran University of Medical Sciences.

\section{CONFLICT OF INTEREST}

The authors declare no conflict of interest related to this work.

\section{REFERENCES}

1. Clinical manifestations and diagnosis of alopecia areata [Internet]. UpToDate, Post TW (Ed), UpToDate, Waltham, MA. 2015 [cited Sep 13, 2016].

2. Alkhalifah A, Alsantali A, Wang E, McElwee KJ, Shapiro J. Alopecia areata update: part I. Clinical picture, histopathology, and pathogenesis. $J$ Am Acad Dermatol 2010;62:177-88, quiz 189-90. doi: 10.1016/j. jaad.2009.10.032.

3. Suerbaum S, Michetti P. Helicobacter pylori infection. New Engl J Med 2002;347:1175-86. doi: 10.1056/NEJM$\mathrm{ra} 020542$

4. Correa P, Piazuelo MB. Natural history of Helicobacter pylori infection. Dig Liver Dis 2008;40:490-6. doi: 10.1016/j.dld.2008.02.035

5. Mini R, Figura N, D'Ambrosio C, Braconi D, Bernardini G, Di Simplicio F, et al. Helicobacter pylori immunoproteomes in case reports of rosacea and chronic urticaria. Proteomics 2005;5:777-87. doi: 10.1002/pmic.200401094

6. Galadari IH, Sheriff MO. The role of Helicobacter pylori in urticaria and atopic dermatitis. Skinmed 2006;5:172-6. doi: 10.1111/j.1540-9740.2006.04646.x

7. Abdou AG, Elshayeb EI, Farag AG, Elnaidany NF. Helicobacter pylori infection in patients with chron- 
ic urticaria: correlation with pathologic findings in gastric biopsies. Int $J$ Dermatol 2009;48:464-9. doi: 10.1111/j.1365-4632.2009.04042.x.

8. Ali M, Whitehead M. Clearance of chronic psoriasis after eradication therapy for Helicobacter pylori infection. J Eur Acad Dermatol Venereol 2008;22:753-4. doi: 10.1111/j.1468-3083.2007.02452.x

9. Hubner AM, Tenbaum SP. Complete remission of palmoplantar psoriasis through Helicobacter pylori eradication: a case report. Clin Exp Dermatol 2008;33:339-40. doi: 10.1111/j.1365-2230.2007.02634.x.

10. Reinauer S, Megahed M, Goerz G, Ruzicka T, Borchard F, Susanto F, et al. Schönlein-Henoch purpura associated with gastric Helicobacter pylori infection. J Am Acad Dermatol 1995;33:876-9. doi: 10.1016/0190-9622(95)90426-3

11. Avcı O, Ellidokuz E, Şimşek I, Büyükgebiz B, Güneş A. Helicobacter pylori and Behçet's disease. Dermatology 1999;199:140-3. doi:10.1159/000018221

12. Imamura Y, Kurokawa M, Yoshikawa H, Nara K, Takada $\mathrm{E}$, Masuda $\mathrm{C}$, et al. Involvement of Th1 cells and heat shock protein 60 in the pathogenesis of intestinal Behcet's disease. Clin Exp Immunol 2005;139:371-8. doi: 10.1111/j.1365-2249.2005.02695.x

13. Kandyil R, Satya NS, Swerlick RA. Chronic pruritus associated with Helicobacter pylori. J Cutan Med Surg 2002;6:103-8. doi: 10.1007/s10227-001-0032-y

14. Reinauer S, Goerz G, Ruzicka T, Susanto F, Humfeld S, Reinauer H. Helicobacter pylori in patients with systemic sclerosis: detection with the 13C-urea breath test and eradication. Acta Derm Venereol 1994;74:361-3.

15. Yazawa N, Fujimoto M, Kikuchi K, Kubo M, Ihn H, Sato $\mathrm{S}$, et al. High seroprevalence of Helicobacter pylori infection in patients with systemic sclerosis: association with esophageal involvement. J Rheumatol 1998;25:650-3.

16. Aragona P, Magazzu G, Macchia G, Bartolone S, Di Pasquale G, Vitali C, et al. Presence of antibodies against Helicobacter pylori and its heat-shock protein 60 in the serum of patients with Sjogren's syndrome. J Rheumatol 1999;26:1306-11.

17. Sorrentino D, Faller G, DeVita S, Avellini C, Labombarda A, Ferraccioli G, et al. Helicobacter pylori associated antigastric autoantibodies: role in Sjögren's syndrome gastritis. Helicobacter 2004;9:46-53. doi: 10.1111/j.10834389.2004.00197.x

18. Kürkçüoğlu N, Aksoy F. Sweet's syndrome associated with Helicobacter pylori infection. J Am Acad Dermatol 1997;37:123-4. doi: 10.1016/S0190-9622(97)70225-1

19. Gasbarrini A, De Luca A, Fiore G, Gambrielli M, Franceschi F, Ojetti V, et al. Beneficial effects of Helicobacter pylori eradication on migraine. Hepato-gastroenterology 1997;45:765-70.

20. Kapp A. Helicobacter pylori infection in skin diseases. $A m$ J Clin Dermatol 2002;3:273-82.

21. Hernando-Harder AC, Booken N, Goerdt S, Singer MV,
Harder H. Helicobacter pylori infection and dermatologic diseases. Eur J Dermatol 2009;19:431-44. doi: 10.1684/ ejd.2009.0739.

22. Negrini R, Savio A, Poiesi C, Appelmelk B, Buffoli F, Paterlini A, et al. Antigenic mimicry between Helicobacter pylori and gastric mucosa in the pathogenesis of body atrophic gastritis. Gastroenterology 1996;111:655-65. doi: 10.1053/gast.1996.v111.pm8780570

23. Gasbarrini A, Franceschi F, Armuzzi A, Ojetti V, Candelli $\mathrm{M}$, Torre ES, et al. Extradigestive manifestations of Helicobacter pylori gastric infection. Gut 1999;45(suppl 1):I9I12. doi:10.1136/gut.45.2008.i9

24. Yoshida N, Granger DN, Evans Jr DJ, Evans DG, Graham DY, Anderson DC, et al. Mechanisms involved in Helicobacter pylori-induced inflammation. Gastroenterology 1993;105:1431-40. doi: 10.1016/0016-5085(93)90148-6

25. Gasbarrini A, Franceschi F, Gasbarrini G, Pola P. Extraintestinal pathology associated with Helicobacter infection. Eur J Gastroenterol Hepatol 1997;9:231-3.

26. Mendall M, Patel P, Ballam L, Strachan D, Northfield T. $\mathrm{C}$ reactive protein and its relation to cardiovascular risk factors: a population based cross sectional study. BMJ 1996;312:1061-5. doi: 10.1136/bmj.312.7038.1061

27. Ahmed A, Holton J, Vaira D, Smith S, Hoult J. Eicosanoid synthesis and Helicobacter pylori associated gastritis: increase in leukotriene $\mathrm{C} 4$ generation associated with H. pylori colonization. Prostaglandins 1992;44:75-86. doi:/10.1016/0090-6980(92)90109-7

28. Juhlin L, Michaelsson G. Cutaneous reactions to kallikrein, bradykinin and histamine in healthy subjects and in patients with urticaria. Acta Derm Venereol. 1969;49:26-36.

29. Abdel-Hafez HZ, Mahran AM, Hofny ER, Attallah DAA, Sayed DS, Rashed HAG. Is Helicobacter pylori infection associated with alopecia areata? J Cosmet Dermatol 2009;8:52-5. doi: 10.1111/j.1473-2165.2009.00424.x.

30. Campuzano-Maya G. Cure of alopecia areata after eradication of Helicobacter pylori: a new association? World J Gastroenterol 2011;17:3165-70. doi: 10.3748/wjg.v17. i2 26.3165 .

31. Rigopoulos D, Katsambas A, Karalexis A, Papatheodorou $\mathrm{G}$, Rokkas T. No increased prevalence of Helicobacter pylori in patients with alopecia areata. $J$ Am Acad Dermatol 2002;46:141. doi: 10.1067/mjd.2002.117255

32. Rebora A, Drago F, Picciotto A. Helicobacter pylori in patients with rosacea. Am J Gastroenterol 1994;89:1603-4.

33. Machet L, Vaillant L, Machet M, Büchler M, Lorette G. Schönlein-Henoch purpura associated with gastric Helicobacter pylori infection. Dermatology 1997;194:86. doi: $10.1159 / 000246068$

34. Farina G, Rosato E, Francia C, Proietti M, Donato G, Ammendolea $\mathrm{C}$, et al. High incidence of Helicobacter pylori infection in patients with systemic sclerosis: association with Sicca Syndrome. Int J Immunopathol Pharmacol 2001;14:81-85. 